[Bull. Agr. Chem. Soc. Japan, Vol. 23, No. 6, p. 528 532, 1959]

\title{
Influence of Smoking Procedures on Combustion Temperature of Cigarettes and the Nicotine Content of Cigarette Smoke*
}

\author{
By Yūsuke Kobashi, Sōichi Sakaguchi and Masao Izawa \\ Tobacco Research Department, Central Research Institute, Japan Monopoly Corporation
}

Received March 12, 1959

\begin{abstract}
In order to establish fundamental knowledge on the combustion mechanism of tobacco, the effects of smoking procedures on both combustion temperature of cigarettes and the amount of nicotine transferred into cigarette smoke were investigated. The combustion temperatures measured with fine thermocouples specially devised, and an excellent responsive autorecording potentiometer, were $794 \sim 827^{\circ} \mathrm{C}$, irrespective of smoking procedures. The free burning temperature obtained was $746^{\circ} \mathrm{C}$.

When the cigarette was smoked up to a definite length $(45 \mathrm{~mm})$ from the lighted end, the amount of nicotine in cigarette smoke increased with increment in puff velocity, showing almost a linear curve.
\end{abstract}

Recently, numerous investigations have been conducted on the measurement of combustion temperatures of cigarettes, cigars and pipe tobaccos by many workers, from the physiological viewpoint.

Wynder ${ }^{11}$, using an iron-constantan thermocouple, reported the combustion temperature of cigarette to be $682^{\circ} \mathrm{C}$. Seelkopf ${ }^{23}$ found the average temperature to be $742^{\circ} \mathrm{C}$ with a platinum and platinum-rhodium thermocouple under the conditions of puff duration of $2.5 \mathrm{sec}$. $\mathrm{Lam}^{3}$, using a $0.2 \mathrm{~mm}$. diameter iron-constantan thermocouple, reported that the temperatures of cigarettes, cigarillos and cigars were $866^{\circ} \mathrm{C}$, $822^{\circ} \mathrm{C}$, and $813^{\circ} \mathrm{C}$, respectively. Greene ${ }^{4)}$, using 28-gauge chromel-alumel thermocouples, found that the temperatures of cigarettes $\left(610 \sim 740^{\circ} \mathrm{C}\right)$, of cigars $\left(580 \sim 660^{\circ} \mathrm{C}\right)$ and of pipes $\left(540 \sim 590^{\circ} \mathrm{C}\right)$. Harlow $^{53}$, using No. $40 \mathrm{~B} \& \mathrm{~S}$ gauge platinum and platinum-rhodium thermocouples, measured the temperature as $774^{\circ} \mathrm{G}$ under the conditions of $35 \mathrm{ml} / \mathrm{sec}$. puff velocity and a two second-

* Studies on the thermal decomposition of tobacco alkoloids. Part I.

1) E. L. Wynder, Cancer Res., 13, 855-864 (1953i.

2) C. Seelkopf, Z. Lebensm. Untersuch. u. -Forsch., 100, 218. $222(1955)$.

3) J. Lam, Acta pabol. Microbiol. Scand., 36, 503-510 (1955i.

4) C. Greene, Science, 122, 514 (1955).

5) E.S. Harlow, Science, 123, 226 (1956). puff duration. He also found the free-burning temperature to be $746^{\circ} \mathrm{C}$. Ermala ${ }^{6)}$ reported that the temperatures of cigarettes, cigars and pipes were $470 \sim 812^{\circ} \mathrm{C}, 380 \sim 620^{\circ} \mathrm{C}$ and $380 \sim$ $620^{\circ} \mathrm{C}$, respectively. Touey ${ }^{7)}$, very recently, indicated that most of the reported temperatures were obtained under poorly defined smoking conditions; and, his study was carried out in an air-conditioned room, and the cigarettes used were selected on the basis of moisture content, air flow resistance and weight. The combustion temperatures reported by Touey were in the range of $873 \sim 890^{\circ} \mathrm{C}$, regardless of smoking conditions.

Nicotine is the most important tobacco smoke constituent, and, with other related alkaloids, its behavior accompanied with smoking has long been a subject of wide interest. An appreciable amount of works in concern of their identification $^{82}$, determination ${ }^{9,10,11}$, and pyrolysis of nicotine $^{12}$ have been reported in the literature.

\footnotetext{
61 P. Ermala, Cancer Res., 16, 490-495 (1956)

7) G.P. Touey, Tobacio, 144, 88-92 (1957).

8) L. Leiserson, Anal. Cbam., 27, 1129 (1955).

9) J. A. Bradford. W. R. Hatlan and H. R. Hanmer, Ind. Eng. Chem., 28, 836-839 (1936).

10) C. Pyriki, Ber. Inst. Tobak Forschung Wohlsdolf-Beendorf, 1954, No. 1, 62.

11) P. H. Latimer, Jr., Research Department, R. J. Reynolds Tobacco Co., Their unpublished data (1955).

12) A. Eisner, J. Am. Cbem. Soc, 66, 911 (1944).
} 
In previous studies ${ }^{18,14)}$ conducted on cigarette smoke, it has been demonstrated that the amount of nicotine in cigarette smoke exceedingly increases accompanied with increment of the smoked length of cigarette.

The work reported here is concerned with the effects of smoking procedures on both combustion temperature and the amount of nicotine transferred into the main-stream, using domestic commercial regular-size cigarettes which were selected on the basis of moisture content and weight.

\section{EXPERIMENTAL}

Preparation of Sample and Smoking Conditions The cigarettes used were of $70 \mathrm{~mm}$-length and blended with domestic flue cured, Indian flue cured, domestic naturally cured and Indian naturally cured tobaccos. After being conditioned to $10.93 \%$ moisture content with a relative humidity of $58 \%$ at $20^{\circ} \mathrm{C}$, the cigarettes falling in the weight range of $0.960 \mathrm{~g} \pm 13 \mathrm{mg}$.

The smoking conditions were as follows: Puff velocities $-5 \mathrm{ml} / \mathrm{sec}, 10 \mathrm{ml} / \mathrm{sec}, 20 \mathrm{ml} / \mathrm{sec}, 40 \mathrm{ml} / \mathrm{sec}$ and $60 \mathrm{ml} / \mathrm{sec}$. Puff duration-two seconds, twice per minute. In all experiments, the cigarettes were smoked up to a definite length $(45 \mathrm{~mm})$ from the lighted end. Smoking experiments were carried out in a room maintained at relative humidity of $59.7 \% \pm 1.6 \%$ and at $19.4 \pm 1{ }^{\circ} \mathrm{C}$.

Cigarette Smoking Procedure A diagram of the apparatus used for smoking is shown in Fig. 1. The

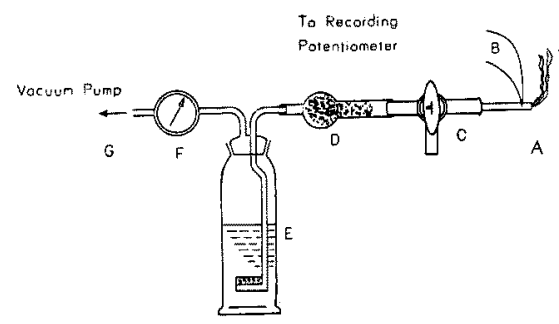

FIG. 1. Smoking Apparatus

A: Cigarette

B: Platinum and Platinum-Rhodium Thermocouple

C. Three-way Stopcock

$\mathrm{D}$ : Absorbent Cotton of ca. $5 \mathrm{~g}$. impregnated with $5 \% \mathrm{HCl}$.

E : Washing Bottle Contg. $\mathrm{H}_{2} \mathrm{O}$

F: Flowmeter

G: Vaculan Pump

13 M. Izawa and Y. Kobashi, J. Agr. Cbem. Soc. Japan, 29, 754 (1955).

14) M. Izawa and $Y$. Kobashi, ibid., 30, 332 (1956). cigarette was inserted into the tube-end of the threeway stop cock $\mathrm{C}$, and covered air-tightly with a short strip of rubber tube, and the cigarette end connected with the rubber tube was sealed with Duco cement to avoid leakage of air. Suction for the puff was created by a vacuum pump $G$ which was connected with a flowmeter $F$, and puff velocities were adjusted by this flowmeter. The puffing action was accomplished by turning the three-way stop cock $\mathbf{C}$ by hand. A cotton plug approximately $5 \mathrm{~g}$ in weight and impregnated with $2 \mathrm{ml}$ of $5 \% \mathrm{HCl}$ was filled in a glass tube $\mathrm{D}$, and most of the nicotine in the cigarette smoke was absorbed in the cotton plug. Bottle $\mathbf{E}$ was used for washing out the smoke.

Measurement of Combustion Temperature The combustion temperature of cigarettes were measured by means of a platinum and platinum (87\%)-rhodium (13\%) thermocouple which was inserted into a position of $25 \mathrm{~mm}$ from the lighted -end of cigarette and connected with precisely responsive autorecording potentiometer*, especially deviced for the purpose of the studies of this series. After the wire was inserted at this position, the pin hole pireced by the needle in the cigarette paper was sealed with Duco cement. Twenty readings were made for each study and the reliable temperatures were calculated at a confidence level of $95 \%$.

Selection of Thermocouples For selection of the proper size of the thermocouple, peak temperatures of the combustion zone were measured with thermocouple wires of $0.03 \mathrm{~mm}, 0.05 \mathrm{~mm}$ and $0.2 \mathrm{~mm}$-diameters under the conditions of $20 \mathrm{ml} / \mathrm{sec}$ puff velocity, and two-second durations, twice per minute.

Determination of Nicotine in Cigarette Smoke After two cigarettes were smoked, the filling in tube $D$ and the washed liquid of cock $\mathrm{G}$ in Fig. 1 were combined and steam-distilled according to the method of Griffith and Jeffre ${ }^{15)}$, and the distillate was then subjected to spectrophotometric determination of nicotine as described by Willits ${ }^{16)}$. Each value reported is the average of five experiments.

\section{RESULTS AND DISCUSSION}

Selection of Proper Thermocouple wire The average combustion temperature obtained with $0.05 \mathrm{~mm}$-wire was measured as $812 \pm 11.1^{\circ} \mathrm{C}$, and was not significantly different from $815 \pm 15.9^{\circ} \mathrm{C}$ obtained $0.03 \mathrm{~mm}$-wire. However, the average temperature of the $0.2 \mathrm{~mm}$-wire

* Shimadzu's Electronic Temperature Recorder Type ARP 21.

15) R. B. Griffith, R.N. Jeff $r y$, Amal. Chem., 20, 307-311 (1948).

16) C. O. Willits, Anal. Chem., 22, 430-434 (1950). 
Table I. PEAK Temperatures obtained with DIFFERENT DIAMETER Thermocouples.
Diameter of wires

$(\mathrm{mm})$

0.03

0.05

0.2
Peak Temperatures

$815 \pm 15.9$

$812 \pm 11.1$

$656 \pm 14.6$
Each value is the average obtained from tweaty experiments.

\section{Table II. Combustion Temperatures caused} by Different Smoking Procedures.
Puff Vel.

(ml/sec.)

without puffing

$\begin{array}{rl}5 & 798 \pm 11.6 \\ 10 & 769 \pm 9.2 \\ 20 & 812 \pm 11.1 \\ 40 & 805 \pm 10.8 \\ 60 & 802 \pm 19.0\end{array}$

Av. Combustion Intermittent puffing

$802 \pm 19.0$
Temperature Continuous puffing

$746 \pm 31.7$

$794 \pm 25.3$

$797 \pm 26.1$

$813 \pm 8.9$

$827 \pm 21.1$

$804 \pm 13.6$
Weighe range of cigarette: $0.960 \mathrm{~g} \pm 13 \mathrm{mg}$ Moisfure content : $10.93 \%$

Room temperature: $19.4{ }^{\circ} \mathrm{C} \pm 1^{\circ} \mathrm{C}$

Relative humidity : $59.7 \% \pm 1.6 \%$

Thermocouple: $0.05 \mathrm{~mm}$ diameter placinum and platinum-rhodium thermocouple wires.

Confidence level of average values of measured combustion temperature is $95 \%$.

Each value is the average obtained from twenty experiments.

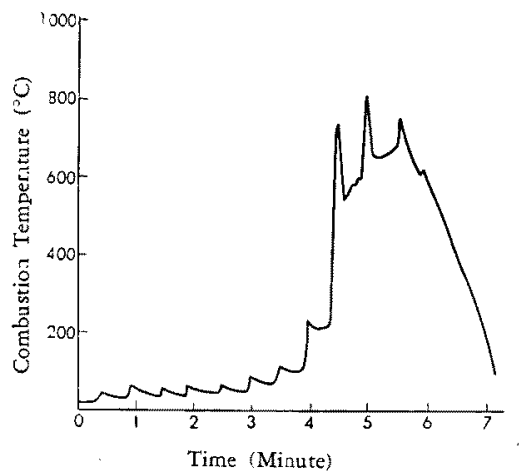

FIG. 2. Combustion Temperature-Time Curve. (Intermittent Puffing at $20 \mathrm{~mL} / \mathrm{sec}$. Puff Velocity)

showed a remarkably low value such as $656 \pm 14.6^{\circ} \mathrm{C}$. This fact may suggest that the wires of less than $0.05 \mathrm{~mm}$ in diameter would give a more accurate temperature for the measurement of combustion-zone temperature of cigarette. These results are shown in Table $\mathbf{I}$. There- fore, $0.05 \mathrm{~mm}$-diameter thermocouple wires were used throughout subsequent experiments.

Effect of Smoking Procedure on Combustion Temperature As shown in Table II, the free-burning temperature was $746 \pm 31.7^{\circ} \mathrm{C}$, but the combustion temperatures accompanied with puffing were within the limits of $794 \pm 25.3^{\circ} \mathrm{C} \sim 827 \pm 21.1^{\circ} \mathrm{C}$, irrespective of puff velocities and smoking types, with one exception of $769 \pm$ $9.2^{\circ} \mathrm{C}$ at the intermittent puffing of $10 \mathrm{ml} / \mathrm{sec}$. The result that the manner of smoking has no marked influence on combustion temperature is in accordance with the findings of Touey? ${ }^{7}$. This may suggest that the amount of oxygen provided has no marked effect on combustion temperature; thus, the puff velocities or smoking types have no significant effect on combustion temperature. However, the combustion temberatures measured in this experiment were about $80^{\circ} \mathrm{C}$ lower than $873 \sim 890^{\circ} \mathrm{C}$ as measured by Touey ${ }^{7}$. The typical shape of combustions temperature-time is also given in Fig. 2. The reason why the value obtained in this study were lower than that obtained by Touey, and combustion temperature at $10 \mathrm{~mL} / \mathrm{sec}$ intermittent puffing was measured lower than others, must be revealed by further studies.

Nicotine in Cigarette Smoke The amount of nicotine in cigarette smoke at different puff velocities and types of smoking are presented in Table III, and the relation of these results are shown in Fig. 3. These

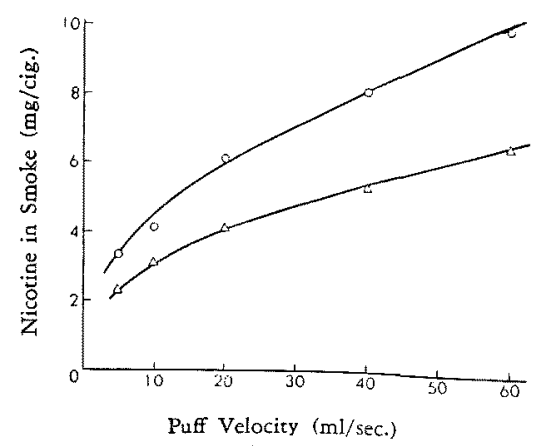

FIG. 3. Nicotine Content in Cigarette Smoke at Different Smoking, Procedures.
$\triangle:$ Intermittent Puffing
$O$ : Continuous Pufing

values were calculated as milligrams per one cigarette. When the cigarettes are smoked up to a definite length from the lighted end, $45 \mathrm{~mm}$, the amount of nicotine transferred into cigarette smoke showed a rise in an 
Table III. Nicotine Content in Cigarette Smoke at Different Smoking.

\begin{tabular}{|c|c|c|c|c|c|c|c|}
\hline $\begin{array}{l}\text { Puff } \\
\text { Vel. }\end{array}$ & $\begin{array}{l}\text { Puff } \\
\text { Number } x \text { \} }\end{array}$ & $\begin{array}{l}\text { Nictone in } \\
\text { smokeb) }\end{array}$ & $\begin{array}{l}\text { Nicotine in } \\
\text { smoke vs. Nico- } \\
\text { tine in burnt } \\
\text { portion of } \\
\text { cigarette }\end{array}$ & $\begin{array}{l}\text { Time required } \\
\text { for } 45 \mathrm{~mm} \text {. } \\
\text { burning on } \\
\text { contin. puffinge) }\end{array}$ & $\begin{array}{l}\text { Time required } \\
\text { for } 1 \mathrm{~mm} \\
\text { burning* }\end{array}$ & $\begin{array}{l}\text { The length of } \\
\text { burnt portion } \\
\text { for } 1 \text { second }\end{array}$ & $\begin{array}{l}\text { Smoked length } \\
\text { in an actual } \\
\text { puff action at } \\
\text { intermittent } \\
\text { puffing** }\end{array}$ \\
\hline
\end{tabular}

\begin{tabular}{|c|c|c|c|c|c|c|c|c|c|}
\hline \multicolumn{2}{|c|}{$(\mathrm{ml} / \mathrm{sec})}$. & $(\widetilde{\mathrm{mg}})$ & $\widehat{(\mathrm{mg})}$ & $(\%)$ & $(\%)$ & (sec.) & (sec.) & $(\mathrm{mm})$ & $(\mathrm{mm})$ \\
\hline 5 & 20.0 & 2.38 & 3.29 & 13.7 & 19.0 & 110.3 & 2.45 & 0.41 & 16.4 \\
\hline 10 & 16.5 & 3.07 & 4.10 & 17.7 & 23.7 & 65.6 & 1.46 & 0.69 & 22.8 \\
\hline 20 & 13.5 & 4.05 & 6.16 & 23.4 & 35.6 & 41.0 & 0.91 & 1.10 & 29.8 \\
\hline 40 & 10.5 & 5.40 & 8.12 & 33.2 & 47.0 & 28.5 & 0.63 & 1.58 & 33.2 \\
\hline 60 & 9.5 & 6.65 & 9.90 & 38.5 & 57.2 & 26.2 & 0.58 & $\mathrm{I} .72$ & 32.5 \\
\hline
\end{tabular}

almost linear curve, from $2.38 \mathrm{mg}(5 \mathrm{ml} / \mathrm{sec})$ to $6.65 \mathrm{mg}$ $(60 \mathrm{ml} / \mathrm{sec})$ for intermittent puffing. In the case of continuous puffing, the rise was from $3.29 \mathrm{mg}(5 \mathrm{ml} / \mathrm{sec})$ to $9.90 \mathrm{mg}(60 \mathrm{ml} / \mathrm{sec})$.

As shown in Table III (8th column)*, in case of continuous puffing, the time required for burning of $1 \mathrm{~mm}$-length of cigarette during smoking-action was shortened with increment of puff velocity from $2.45 \mathrm{sec}$ $(5 \mathrm{ml} / \mathrm{sec})$ to $0.58 \mathrm{sec}(60 \mathrm{ml} / \mathrm{sec})$. This may be a cause of the results obtained, that is, the time required for nicotine is subjected to thermal decomposition, diminishes less and less with the increase in puff velocity, therefore, the amount of pyrolyzed nicotine decreases with the increase in puff velocity. On the other hand, as the changes in puff velocity and the smoking type did not have effect on the combustion temperature of cigarettes, the increment of the amount of nicotine in cigarette smoke with the increase in puff velocity may be assumed that the time in which nicotine is subjected to thermal decomposition during actual puffing action, decreases according to increase in puff velocity.

In the case of intermittent puffing, as shown in Table III (10th column)**, the consumed cigarette length during actual puff action was not constant but varied from $16.4 \mathrm{~mm}(5 \mathrm{ml} / \mathrm{sec})$ to $32.5 \mathrm{~mm}(60 \mathrm{ml} / \mathrm{sec})$, according to the increase in puff velocity. Consequently, it is expected that the amount of nicotine transferred into the main stream increases with the increase in puff velocity, while the dispersed amount of nicotine into the side stream decreases.

In the case of intermittent puffing, it is therefore con-

* These values were derived from the consumed cigarette length, $45 \mathrm{~mm}$., and values shown in the 7 th column of Table III. * $*$ These values were derived from the values given in the and column and 9 th columa, of Table III. sidered that the increase in the amount of nicotine in cigarette smoke with increase of puff velocity is caused by altering smoked-length of the cigarette during actual puff-action, besides a similar reason to be explained for continuous puffed smoking.

\section{SUMMARY}

The work described in this paper has been undertaken to clarify the effects of smoking procedures on combustion temperature of cigarettes and the nicotine content in smoke of domestic commercial cigarettes. Intermittent and continuous smoking were carried out under different puff velocities by means of an artificial smoking apparatus. The measurement of combustion-zone temperatures developed during from $5 \mathrm{ml} / \mathrm{sec}$. to $60 \mathrm{ml} / \mathrm{sec}$. puff velocities were made by $0.05 \mathrm{~mm}$.-diameter thermocouples made of platinum and platinum (87\%)-rhodium (13\%) wire and by an excellent responsive autorecording potentiometer. These values were $794 \pm 25.3^{\circ} \mathrm{C}$ $\sim 827 \pm 21.1^{\circ} \mathrm{C}$, irrespective of smoking procedures, but with an exception of $769 \pm 9.2^{\circ} \mathrm{C}$ of $10 \mathrm{ml} / \mathrm{sec}$. intermittent puffing. However, the free-burning temperature was $746 \pm 31.7^{\circ} \mathrm{C}$.

When the cigarette was consumed up to 45 $\mathrm{mm}$. in length from the lighted end, the nicotine content in cigarette smoke increased with puff velocity. These values rised linearly from 2.38 $\mathrm{mg}\left(5 \mathrm{ml} / \mathrm{sec}_{\text {. }}\right)$ to $6.65 \mathrm{mg}(60 \mathrm{ml} / \mathrm{sec}$.) for intermittent puffing, and from $3.29 \mathrm{mg}(5 \mathrm{ml} / \mathrm{sec}$.) to $9.90 \mathrm{mg}(60 \mathrm{~m} / \mathrm{sec}$.) for continuous puffing. 
Acknowledgements The authors are indebted to Prof. Yataro Obata, Department of Agricultural Chemistry, Hokkaido University, for his invaluable advice and encouragement. Acknowledgements are made to Mr. Sadao Nakamura,
Director of this Institute, and to Dr. Isao Onishi, Chief of this Department, for their encouragement, and permission to publish this work. Thanks are also due to Miss C. Tokura and Mrs. H. Hōshaku for their technical assistance.

[Bull. Agr. Chem. Soc. Japan, Vol. 23, No. 6, p. 532 535, 1959]

\title{
On the Influence of Moisture Content in Cigarettes on Combustion Temperature and Transferred Amount of Nicotine into Cigarettes Smoke*
}

\author{
By Yüsuke Kobashi, Sōichi Sakaguchi and Masao Izawa \\ Tobacco Research Department, Central Research Institute, Japan Monopoly Corporation \\ Received March 12, 1959
}

\begin{abstract}
The effects of moisture content of cigarettes on both combustion temperature and the amount of nicotine transferred into the smoke were studied under different smoking conditions. The combustion temperatures of domestic commercial blended cigarettes were not affected by smoking procedures or amount of moisture in the cigarette. No significant differences in the amount of nicotine transferred into smoke were observed between the cigarettes with medium (10.9\%) and high (15.4\%) moisture contents, while the values obtained from the low moisture content $(6.6 \%)$ cigarettes were always slightly higher than those obtained from medium or high moisture content cigarette.
\end{abstract}

In the author's previous study on cigarette smoke ${ }^{1}$, it has been shown that combustion temperature of cigarettes are not affected by either puff velocities or smoking types i. e., intermittent and continuous puffing; but, in contrary to this, the amount of nicotine contained in the smoke, shows a rise approaching a linear-curve in accordance with the increase in puff velocity.

It has long been recognized that the smoke of cigarettes having a low moisture content is more irritant to the throat than that of cigarettes having a high moisture content ${ }^{2,3}$, and that

\footnotetext{
* Studies on the thermal decomposition of tobacco alkaloids. Part II.

1) Yûsuke Kobashi, Sôichi Sakaguchi and Masao Izawa, This Bulletin, 23, 528 (1959).

2) P.S, Lasson, Ind. Eng. Chem., 44, 279 (1952).

3) J.K. Finnegan and P.S. Larson, J. Pharmacol. Exptl. Therap.,
}

the amount of nicotine contained in the smoke of dry cigarettes is comparatively richer than that of moist ones's). However, no literature dealing with the effect of the moisture content of cigarettes on combustion temperature and on the amount of nicotine transferred into smoke under different smoking conditions, has yet been found. The present study was performed in order to clarify the problem of thermal decomposition of nicotine in tobacco and the transfer of alkaloids into the smoke.

\section{EXPERIMENTAL}

Preparation of Sample and Smoking Conditions Sample cigarettes of $70 \mathrm{~mm}$ Standard length, blended

4) E. Waser, Z. Lebensm.-Untersuch. u. -Forsch., 65, 470 (1932). 